\title{
An overview of knowledge sharing in new product development
}

\section{James Gao \& Alain Bernard}

The International Journal of Advanced Manufacturing Technology ISSN 0268-3768

Int J Adv Manuf Technol DOI 10.1007/s00170-017-0140-5

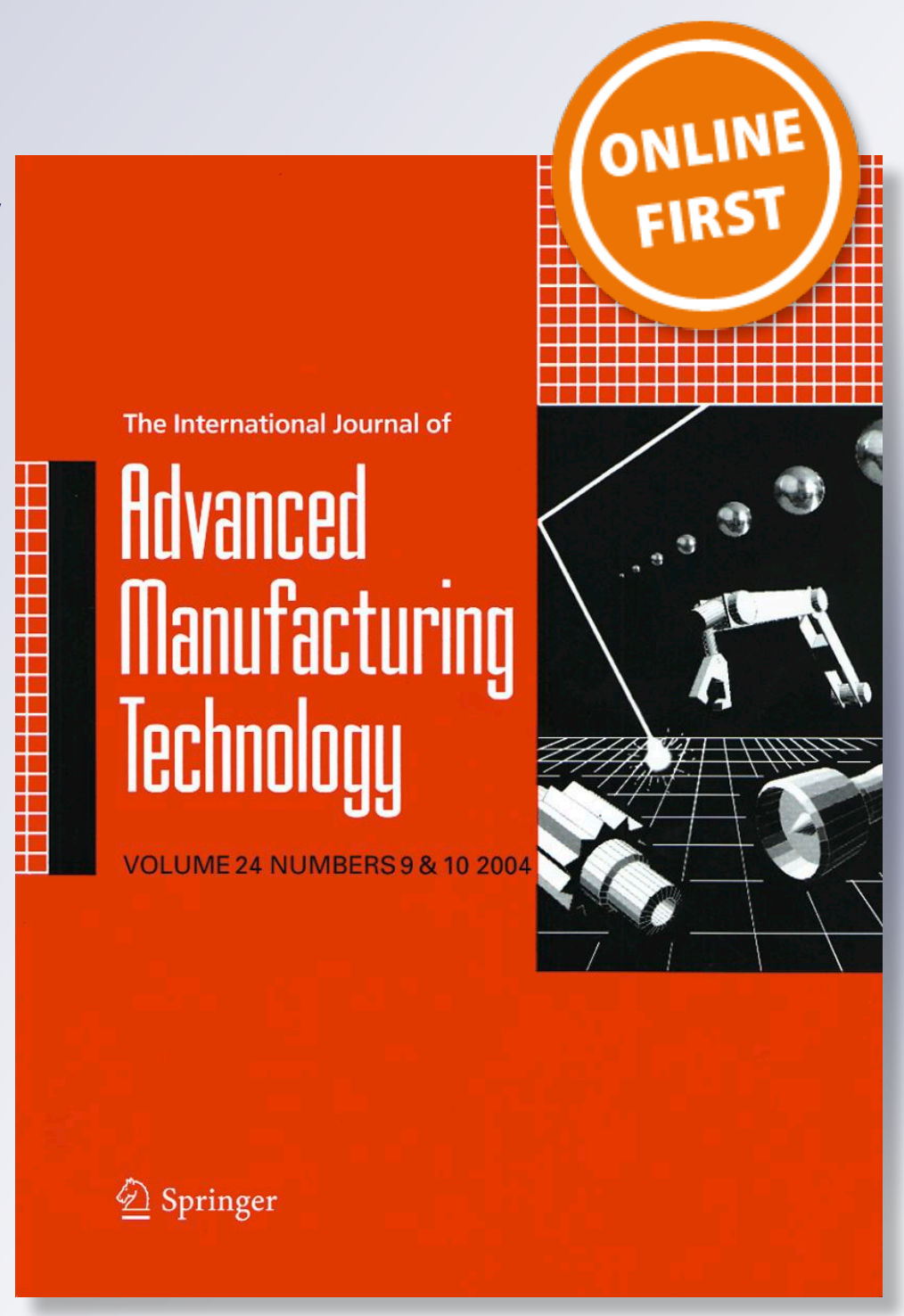

算 Springer 
Your article is published under the Creative Commons Attribution license which allows users to read, copy, distribute and make derivative works, as long as the author of the original work is cited. You may selfarchive this article on your own website, an institutional repository or funder's repository and make it publicly available immediately. 


\title{
An overview of knowledge sharing in new product development
}

\author{
James Gao $^{1}$ - Alain Bernard ${ }^{2}$
}

Received: 16 January 2017 / Accepted: 6 February 2017

(C) The Author(s) 2017. This article is published with open access at Springerlink.com

\begin{abstract}
This paper provides an overview of some of the issues in knowledge management related to the sharing of knowledge in new product development. Previous research and concepts reported by international researchers and examples of the research projects carried out by the authors will be introduced. The paper first provides an overview of the history and importance of innovation and challenges in manufacturing. Then, the importance of new product development in the sustainable success of manufacturing enterprises in the globalised business operations is discussed. The formalisation and modelling of product development processes will also be introduced. The concept and different definitions of knowledge management by previous researchers are then introduced, with further discussion on knowledge sharing. At this point, the authors' research in knowledge sharing is also introduced. Finally, the trend of using social media and Enterprise 2 technologies in knowledge management and sharing is introduced using the recent research projects of the authors as examples.
\end{abstract}

Keywords Knowledge management $\cdot$ Knowledge sharing · New product development

James Gao

j.gao@greenwich.ac.uk

1 Faculty of Engineering and Science, University of Greenwich, Chatham Maritime, Kent ME4 4TB, UK

2 Product Design and Industrial Systems Department, Ecole Centrale de Nantes, LS2N UMR CNRS 6004, BP 92101, 44321 Nantes Cedex 3, France

\section{Innovation in manufacturing}

Manufacturing was forged in the fires of the industrial revolution in the late eighteenth century [1]. Spreading rapidly from Britain to Europe, North America and beyond, it drove the creation of wealth in those regions. In the early twentieth century, Henry Ford's innovative use of the assembly line in the automotive industry helped trigger the widespread adoption of mass production, which in turn led to a lower cost of production for many manufactured goods [2]. Products that were previously the preserve of the wealthy became accessible to the less well-offs and so demand for them grew. In this way, the cost of manufacturing products became a focus of competition for many manufacturers.

A report from the National Association of Manufacturers [3] in the USA claimed that more than three-quarters of global trade was in the form of manufactured goods in 2005. Manufacturing continues to play a significant role in the economic prosperity of Western economies [4]. However, the high labour costs in developed countries have encouraged a migration of manufacturing production to lower wage economies. This process has been supported by lower transport costs, the reduction or removal of trade tariffs and developments in communication technologies. In order to address this challenge, governments of developed countries have advocated a shift towards the development of high-value added products.

During the last few decades, manufacturing industry has reduced its influence on most Western countries' GDP. Specifically in the UK, manufacturing industry employs approximately 2.6 million people and accounted for $10 \%$ of the UK GDP in 2014 [5]. In the last decade, manufacturing industry has underperformed and suffered a significant decline during the 2008/09 recession. After a short period of growth, it declined again in early 2012. More recently, however, 
economic data suggests that manufacturing industry is showing significant signs of strengthening and growing, both in the UK and globally. Manufacturing dominates UK Research and Development (R\&D) spending. In 2012, R\&D spending in manufacturing accounts for $72 \%$ of total R\&D funding within the UK [6].

Commercial organisations have sought to increase profits by investing resources in both the creation of new products and discovering new methods of manufacturing and delivering existing products. Such developments may be referred to as 'innovations' [7]. The Department of Trade and Industry [8] in the UK published a strategy document for UK manufacturing which identifies innovation as one of the seven 'pillars' required to build a successful manufacturing industry.

A benchmarking study of firms in the USA from 2003 conducted by American Productivity and Control, reported that in the proceeding 3 years, new products had accounted for an average of almost $28 \%$ of sales [9]. Innovation and new products have emerged as a focus of competition for businesses [10]. Furthermore, the process of product development is considered to be a 'critical' factor for the manufacturing businesses that aspire to prosper in the competitive markets.

\section{Emergence of global product development}

Merely engaging in the development of a new product is no guarantee that the project will be successful. New product development (NPD) projects are effectively complex business processes involving individuals from different functions, which will typically include design, testing, manufacturing and marketing [11]. For some years scholars have maintained that project failures are in part caused by the lack of a systematic approach to these complex projects and have encouraged the use of formal process models to support managerial decision-making [12]. Effectively, these systems serve as methodologies for the application of managerial rigour and discipline to the innovation process. Cooper [13] defined the formal NPD process as 'a formal blueprint, roadmap template or thought process for driving a new product from the idea stage through to market launch and beyond'.

A commonly used model is the cross-functional stage-gate model which Griffin [14] indicated is employed by almost $60 \%$ of firms in the USA. This model divides the NPD process into discrete stages, each of which is followed by a review gate. Each stage can be broken down into a collection of predefined, cross-functional and concurrent tasks, which are executed by cross-functional teams. The importance of such a formal process model and its connection to best practice is well established. Fredericks [15] showed that crossfunctional involvement in product development is dependent on a collective understanding of the tasks required at different phases of the NPD process. Chandrasegaran et al. [16] have investigated the evolution and main challenges with respect to knowledge representation in product design systems, which is a critical issue when speaking of NPD.

Furthermore, recent decades have witnessed the emergence of the global product development (GPD) phenomenon. They characterised global product development team members as being geographically dispersed, speaking different languages and originating from different cultural backgrounds. This differentiates them from co-located teams who work in a single locale, such as region of a country or city, and share a common language. Eppinger and Chitkara [17] stressed that the use of global resources is not, as in previous years, to exploit low labour costs, but rather to exploit globally distributed NPD expertise that cannot be obtained in one locale in order to achieve growth and innovation. McDonough et al. [18] warned that global product development teams will become more prevalent, and therefore, research is required to develop methods of obtaining levels of performance from GPD teams that match those already available from their co-located counterparts.

The interactions between the different teams are crucial for any project to succeed. Getting communication right between the different NPD teams and re-using the knowledge that already exists within a company can determine whether a new product is launched on time and on budget. Recreating and recollecting the same knowledge for different projects is both costly and time consuming, which shows the importance of capturing and sharing pre-existing knowledge already available among employees, so that further knowledge can be built upon it, which constitutes innovation. Frost [19] provided a list of the symptoms of the failure including inadequate management support, problems with organisational culture, and lack of responsibility and ownership inter alia. From the literature and the investigation findings, there is clear evidence that industry sees potential and value in creating knowledge management $(\mathrm{KM})$ systems. But insufficient attention is given to it and it is sometimes treated as an afterthought.

\section{Knowledge management}

During the mid-1980s, Porter and Millar [20] ventured the idea that information could be used to achieve a competitive advantage. By the 1990s, academics posited that knowledge, rather than capital, would become the main source of wealth in the new economy [21] and it would seem that this transition is indeed taking place. Stewart [22] claimed that information represented three quarters of value added in manufacturing. Nonaka [23] opined that successful companies would be those that are able to create and disseminate knowledge rapidly and then transfer this knowledge into their new products. These ideas have contributed to an increasing interest in knowledge management. 
Knowledge is regarded as the key to innovation, and in order to remain competitive in today's engineering world, it is a crucial asset for organisations that enables them to gain a sustainable competitive edge on their competitors [24]. Improving and creating new ways for how knowledge is captured and shared among NPD engineering teams will determine if companies can capitalise on this valuable, readily available resource. Definitions of knowledge management are many. Ngai and Chan [25] defined knowledge management as follows: 'knowledge management refers to the set process or practice of developing in an organisation the ability to create, capture, evaluate and matrix, store and index, maintain and disseminate the organisation's knowledge'. Some additional definitions and elements could be found in the document proposed by Perry and Bernard [26].

Knowledge management is a discipline that promotes an integrated approach to identifying, capturing, evaluating, retrieving, maintaining and sharing all of an enterprise's information assets. These assets may include databases, documents, policies, procedures, and previously uncaptured expertise and experience from individual workers [27]. Over the years, various KM systems have been developed and have taken many forms, such as purpose-built databases, data capture and workflow solutions, social analytics and engagement solutions or content life cycle management systems, which are all described as process driven solutions.

\section{Knowledge sharing}

Knowledge sharing as the dissemination of information and knowledge within a community is considered to play a crucial role in knowledge management ventures within the organisation. Effective knowledge sharing drives organisational and individual learning, which in turn speeds up and improves the quality of product innovation. It has been shown, through the literature available, that knowledge sharing provides individuals, teams and organisations with the opportunity to improve their work performance as well as creating new ideas and innovations [28]. This clearly indicates that sharing knowledge is primarily a social, interactive and complex process that involves both tacit and explicit knowledge [29].

As already alluded to, new products have become a focus of competition for many manufacturers, and the product development process has become increasingly important to these businesses. Manufacturers are seeking to compete on issues like product quality and the time taken to introduce new products to the market. Such pressures have made the effective sharing of knowledge in the NPD process into a means of achieving a competitive advantage. Consequently, great attention has been focused on the application of knowledge management to new product development. Nonetheless, relatively little heed has been paid to knowledge sharing in the NPD domain [30].

The sharing of knowledge among individuals in an organisation is confounded by an abundance of obstacles. Obstacles to knowledge sharing common to large enterprises, or more specifically, large multinational companies, may concern the individuals working in the organisation or the environment in which these individuals function. For product development teams executing complex cross-functional product development business process, it may reasonably be asserted that further knowledge sharing obstacles will be encountered. Such obstacles have been shown to be detrimental to product development performance. The gaps in shared knowledge could be directly responsible for costly mistakes made in the course of the product development process. Project teams working with high levels of shared knowledge in customers, suppliers and internal capabilities were significantly higher in their process performance outcomes than those teams with low levels of shared knowledge. It is asserted then that it is desirable to eliminate or reduce the impact of obstacles to knowledge sharing in a product development environment. Generally, knowledge lifecycle management [31] has to be considered in order to favour efficient knowledge sharing within companies, and in particular project teams.

Bradfield and Gao [32] presented an exploratory case study conducted at a multinational physical goods manufacturer. This investigation uncovered main barriers to knowledge sharing such as the lack of an explicit definition of the knowledge used and generated in the product development process, and the absence of mechanisms to make this information accessible in a multilingual environment and to disseminate it to NPD project team members. They have developed a prototype method and tool to facilitate knowledge sharing that addresses the identified knowledge sharing barriers. An ontology has been developed that formally defines information about this knowledge and allows it to be captured in a knowledge acquisition tool, thereby creating a knowledge base. A mechanism is provided to permit language labels to be attached to concepts and relations in the ontology, making it accessible to speakers of different languages. A dissemination tool allows the ontology and knowledge base to be viewed via a web browser client.

Zammit et al. [33] carried out an extensive industrial investigation to bring out real industrial requirements in the product development and testing context, and developed methodologies to capture and share testing related knowledge to address the special nature and application context of the integrated global product development and testing operations of multinational companies. They have explored the capabilities of the fast developing social media tools in facilitating the capture and sharing of employee knowledge, especially tacit and unstructured knowledge, and addressing the social aspects of knowledge management. They also explored the benefit of 
using a knowledge framework that is directly driven by the knowledge users by providing both knowledge content and how it is structured, rather than relying on the role of knowledge administrators. The developed methodology with social media, video sharing and storytelling techniques could substantially enhance and extend the capabilities of traditional engineering information management tools, by providing the ability to quickly browse and absorb user-contributed testing knowledge, like lessons learned, suggested product improvement or process training material, and identify specific knowledge experts within a global organisation.

\section{Dynamics of knowledge}

Dynamic KM is a convergence of people and machines working together in harmony to achieve profitable income for the company. Dynamic KM systems aim to support organisational learning so that better informed decisions can be made. With Dynamic KM people will be rewarded for achieved performance metrics that improve the organisation's position in the market place. Nonaka [34] theorised a dynamic spiral to create organisational knowledge depending on the direction of flow of information between people (informal/ tacit) and multimedia (formal/explicit). It would be wrong to assume that simply by reading, writing, watching, recording, listening, talking about a subject means that a person has learned how to apply this knowledge to a real situation to achieve real results. Choi and Lee [35] have defined the dynamic KM style in their empirical investigation. The 'Dynamic' KM style overcomes the drawbacks of using the 'People-orientated' or 'System-orientated' style alone.

However, so far, the dynamic style of KM has rarely been applied to product development. Since product development is about producing something that can be sold, dynamic KM should therefore be closely linked to performance so that people can profit from the value of knowledge [30, 36, 37], and include both technological and cultural factors, to give the highest yield to a company compared to other KM styles. The current popular processes for personal and product continuous improvement include the Performance Development Review, the Product Lifecycle Management process and the Plan-Do-Check-Act ethos. All of the above involve regular face-to-face (F2F) meetings. Therefore, F2F meeting discussion may provide an opportunity to identify who within an organisation uses knowledge to shape the successful development of a product.

Piorkowski et al. [38] proposed a generic dynamic KM framework and developed a prototype F2F meeting capture and indexing tool to be used as part of the dynamic KM framework in the high-value manufacturing industry. The tool was evaluated in a large corporate and a small non-profit making organisation and was successful for both a group stakeholder meeting and also for individual employee profile interviews. A remarkable finding is that the use of video with the F2F interview questions worked very well for employee personal reflective analysis.

Product manufacturers are extending their responsibilities in the whole life cycle by providing services to their customers. In recent years, product service system has become an important research topic to address the special requirements in the new service-driven business model. Wan et al. [39] investigated the various relationships between different stakeholders in high-value machine tools' lifecycle, focusing on knowledge management, communication and the decisionmaking processes. Their research explored the potential application of advanced content management systems, which are widely implemented in the financial, business and government organisations, in the manufacturing engineering domain which has been dominated by traditional engineering information systems. A prototype collaborative maintenance planning system was developed and evaluated which indicated that significant improvement could be achieved and the content management technology has a number of advantages over the traditional engineering information systems, in managing machine tool maintenance and service information including dynamic and unstructured knowledge.

In dealing with dynamic information such as on-line machine tool performance and in-process inspection of machined parts related to machine tool maintenance, $\mathrm{Li}$ et al. [40, 41] reported pioneering investigation and experimental work in on-line monitoring and inspection system based on a new dynamic feature concept (as opposed to traditional static geometry-based feature definition) for modelling the dynamic real-life information to achieve timely and responsive machining control. In their dynamic feature model, the relationships between the interim states of a part (workpiece-in-progress) and associated machining characteristics and knowledge have been investigated and dynamic information linked to different interim features have been modelled and integrated. For machining large-scale freeform surfaces of aerospace structural parts, Li et al. [42] divided the surface into sub-surfaces with respect to changing requirements and the dynamic machining situation, and proposed an innovative rank-two tensor based tool path optimisation method which can significantly improve the machining efficiency of aerospace parts with large and complex freeform surfaces.

The principle of modelling dynamic feature information proposed by $\mathrm{Li}$ et al. has also been used in monitoring and modelling the changing status of complex large-scale aerospace structural parts during machining, and on-line adjusting numerical control parameters by the invention of an integrated flexible fixturing and responsive machining system which automatically compensates the deformation caused by stress release during the machining of large-scale aerospace parts [43, 44]. Previous researchers developed theories to predict 
residual stress, then to predict deformation, which was very inaccurate. Later improved methods used directly measured residual stress to predict deformation, which was still difficult to predicted component deformation accurately during machining. Li et al. directly measured the deformation during machining and used their invented flexible fixturing and automatic machining control mechanism, making a significant step forward in the adaptive machining control technologies for large-scale aerospace structural part manufacturing.

In real-life product development, testing and manufacturing operations, capturing, sharing and making use of on-line explicit knowledge including data and information is very important. On-line and timely updated testing information and knowledge has been achieved by Zammit et al. [45] by their developed framework with social media, video sharing and storytelling techniques which provides the ability to quickly browse and absorb user-contributed testing knowledge, like lessons learned, suggested product improvement or process training material, and identify specific knowledge experts within a global organisation.

Evans et al. [46] reported on an investigative study conducted within a leading aerospace and defence industry organisation to highlight the potential benefits offered by enterprise 2.0 technologies to facilitate employee collaboration during product development activities. Although participants demonstrated a high degree of familiarity with current social media sites and web 2.0 tools, the research suggested that little use is being made of them within the organisation, with employees still relying heavily on traditional means of communication for project collaboration. They proposed and developed a framework to facilitate collaborative knowledge sharing in dispersed aerospace product development, which was applied to the bespoke BAE Systems' engineering lifecycle process with results indicating that Enterprise 2.0 technologies with social media functions offer a more openly innovative environment in which employees may share and receive dynamic knowledge more easily across geographical and functional boundaries.

\section{Summary}

In the authors' previous research experience, and from the literature reviewed and company sponsored research projects carried out, knowledge sharing is regarded by most manufacturing companies as one of the most important issues in knowledge management, for improving efficiency, quality and time to market in new product development. Recent development and fast expanding of social media and Enterprise 2 technologies in non-manufacturing applications have attracted significant interest from traditional engineering industry, including the more conservative defence and aerospace manufacturing enterprises. The other trend is how to deal with the dynamic real-life information, knowledge and communication in manufacturing. Some recent research in this aspect has been introduced in this paper, including the authors' own work. A lot more research and development effort is needed in the future to improve knowledge sharing in new product development to also include technologies such as Internet of Things (IoT) and cyber-physical systems.

Acknowledgements This paper includes introduction of some research projects carried out by previous $\mathrm{PhD}$ students supervised by the authors. More information about these research projects can be found in the cited references.

Open Access This article is distributed under the terms of the Creative Commons Attribution 4.0 International License (http:// creativecommons.org/licenses/by/4.0/), which permits unrestricted use, distribution, and reproduction in any medium, provided you give appropriate credit to the original author(s) and the source, provide a link to the Creative Commons license, and indicate if changes were made.

\section{References}

1. Mantoux P (1961) The industrial revolution in the eighteenth century: an outline of the beginnings of the modern factory system in England. Jonathan Cape, London

2. Norcliffe G (1997) Popeism and Fordism: examining the roots of mass production. Reg Stud 31(3):267-280

3. National Association of Manufacturers (2006) The facts about modern manufacturing, 7 th edn. National Association of Manufacturers (NAM), Washington, DC

4. Elsouri M, Gao J, Owodunni O, Simmonds C, Martin N (2016) An investigation of current challenges in improving manufacturing knowledge management for product design in an aerospace systems manufacturer. Advances in Manufacturing Technology XXXProceedings of the 14th International Conference on Manufacturing Research, ISBN 978-1-61499-667-5 (print)

5. World Bank (2015) United Kindgdom - Data, http://data. worldbank.org/country/united-kingdom

6. Rhodes C (2014) Manufacturing: statistics and policy. E. P. a. S. Section, UK Government.

7. Trott $P$ (2005) Innovation management and new product development, 3rd edn. Financial Times Prentice Hall, Harlow

8. DTI (2004) DTI review of the government's manufacturing strategy: competing in the global economy-the manufacturing strategy two years On. http://www.dti.gov.uk/files/file18188.pdf

9. Kahn KB (2005) The PDMA handbook of new product development, 2nd edn. John Wiley \& Sons Inc., New Jersey, Hoboken

10. Toole AA (2012) The impact of public basic research on industrial innovation: evidence from the pharmaceutical industry. Res Policy 41(1):1-12

11. Kratzer J, Leenders RTAJ, Engelen JMLV (2010) The social network among engineering design teams and their creativity: a case study among teams in two product development programs. Int $\mathrm{J}$ Proj Manag 28(5):428-436

12. Jones O, Stevens G (1999) Evaluating failure in the innovation process: the micropolitics of new product development. R\&D Manag 29(2):167-178

13. Cooper RG (1994) Perspective third-generation new product processes. J Prod Innovat Manag 11(1):3-14 
14. Griffin A (1997) PDMA research on new product development practices: updating trends and benchmarking best practices. J Prod Innovat Manag 14(6):429-458

15. Fredericks E (2005) Cross-functional development in new product development: a resource dependency and human capital perspective. Qualitative Market Research 8(3):327-341

16. Chandrasegaran S, Ramani K, Sriram RD, Horvath I, Bernard A, Harik R, Gao W (2013) The evolution, challenges, and future of knowledge representation in product design systems. Comput Aided Des 45(2):204-228

17. Eppinger SD, Chitkara AR (2006) The new practice of global product development. MIT Sloan Manag Rev 47(4):22-30

18. McDonough EF, Kahn KB, Barczaka G (2001) An investigation of the use of global, virtual, and colocated new product development teams. J Prod Innovat Manag 18(2):110-120

19. Frost A (2014) A Synthesis of Knowledge Management Failure Factors. Retrieved April 1: 2014

20. Porter ME, Millar VE (1985) How information gives you competitive advantage. Harv Bus Rev 63(4):149-160

21. Quinn JB, Anderson P, Finkelstein S (1996) Managing professional intellect: making the most of the best. Harv Bus Rev 74(2):71-80

22. Stewart TA (1998) Intellectual capital: the new wealth of organizations, 1st edn. Nicholas Brealey, London

23. Nonaka I (1991) The knowledge-creating company. Harv Bus Rev 69(6):96-104

24. López-Nicolás C, Meroño-Cerdán ÁL (2011) Strategic knowledge management, innovation and performance. Int J Inf Manag 31(6): 502-509

25. Ngai EWT, Chan EWC (2005) Evaluation of knowledge management tools using AHP. Expert Syst Appl 29(1):889-899

26. Perry N and Bernard A (2016) Knowledge Management, CIRP Encyclopedia of Production Engineering, pp 723-729

27. Meihami B, Meihami H (2014) Knowledge management a way to gain a competitive advantage in firms (evidence of manufacturing companies). International Letters of Social and Humanistic Sciences 03:80-91

28. Cummings JN (2004) Work groups, structural diversity, and knowledge sharing in a global organization. Manag Sci 50(3):352-364

29. Polanyi M, Sen A (2009) The tacit dimension. University of Chicago Press, Chicago

30. Labrousse M, Bernard A (2008) FBS-PPRE, an enterprise knowledge lifecycle model, Methods and tools for effective knowledge life-cycle-management, 285-305, Bernard \& Tichkiewitch edit, Springer

31. Bernard A and Tichkiewitch S (2008) Methods and tools for effective knowledge lifecycle management, published by Springer, DOI 10.1007/978-3-540-78431-9.
32. Bradfield D, Gao JX (2007) A methodology to facilitate knowledge sharing in the new product development process. Int J Prod Res 45(7):1489-1504

33. Zammit J, Gao J, Evans R (2016) Development of a knowledge sharing framework for improving the testing processes in global product development, international journal of product lifecycle management. Inderscience Enterprises Ltd 9(1):1-18

34. Nonaka I (1994) A dynamic theory of organizational knowledge creation. Organ Sci 5:14-37

35. Choi B, Lee H (2003) An empirical investigation of KM styles and their effect on corporate performance. Inform Manage-Amste 40: 403-417

36. Xu Y, Bernard A (2011) Quantifying the value of knowledge within the context of product development. Knowl-Based Syst 24(1):166175. doi:10.1016/j.knosys.2010.08.001

37. Xu Y, Bernard A (2010) Knowledge value chain: an effective tool to measure knowledge value. Int J Comput Integr Manuf 23(11): 957-967. doi:10.1080/0951192X.2010.500677

38. Piorkowski BA, Gao JX, Evans RD, Martin N (2013) A dynamic knowledge management framework for the high value manufacturing industry. Int J Prod Res 51(7):2176-2185

39. Wan S, Li D, Gao J, Roy R, Tong Y (2017) Process and knowledge management in a collaborative maintenance planning system for high value machine tools. Int J Comput Commun 84:14-24

40. Li Y, Wang W, Liu X, Ma Y (2013) Definition and recognition of rib features in aircraft structural part. Int. J. Comput. Integ. M. 27(1):1-19

41. Liu C, Li Y, Shen W (2014) Dynamic feature modelling for closedloop machining process control of complex parts. Int J Comput Integ M 28(7):753-765 http://dx.doi.org/10.1080/0951192X. 2014.900870

42. Liu X, Li Y, Ma S, Lee C (2015) A tool path generation method for freeform surface machining by introducing the tensor property of machining strip width. Comput. Aided Design 66:1-13

43. Zhou Y, Li Y, Wang W (2011) A feature-based fixture design methodology for the manufacturing of aircraft structural parts. Robot Cim-Int Manuf 27(6):986-993

44. Liu C, Li Y, Gao X (2015) Feature-based adaptive numerical control programming method for the environment of changing manufacturing resources. P I Mech Eng B-J Eng 13(5):237-247

45. Zammit J, Gao J, Evans R (2016) Capturing and sharing product development knowledge using storytelling and video sharing, Procedia CIRP, CIRP Ann-Manuf Tech 56 (2016): 440-445.

46. Evans RD, Gao JX, Martin N, Simmonds C (2015) Exploring the benefits of using enterprise 2.0 tools to facilitate collaboration during product development. International journal of product lifecycle management, Inderscience Enterprises 8(3):233-252 